\title{
Saline Infused Sono-Hysterosalpingography; A Step Forward in the Diagnosis of Infertility Due to Tubal Blockage \\ Zaheer Mustafa, ${ }^{1}$ Hamna Wahid, ${ }^{1}$ Sajida Majeed, ${ }^{1}$ Asma Rashid ${ }^{1}$
}

\begin{abstract}
Background: Saline infused Sono hysterosalpingography (SSG) is the new and safe modality as compared to conventional hysterosalpingogrphy (HSG) for diagnosis of tubal blockage.

Objective: To determine the diagnostic accuracy of saline infused Sono hysterosalpingohgraphy, for detection of fallopian tube blockage, in cases with infertility taking conventional hysterosalpingography as gold standard.

Methodology: This was a cross sectional study conducted in Department of Radiology, Sheikh Zayed Hospital, Rahim Yar Khan, conducted from $1^{\text {st }}$ May to $30^{\text {th }}$ November, 2017. A total of 150 cases, with age range of 20-40 years, irrespective of type and duration of infertility, were included. Findings of tubal blockage with saline infused Sono hysterosalpingography (SSG), were compared to conventional hysterosalpingogrphy (HSG). Sensitivity, Specificity, PPV, NPV and Diagnostic accuracy of saline infused Sono-hysterosalpingography, for detection of fallopian tube blockage, in cases with infertility were calculated, taking conventional hysterosalpingography as gold standard.

Results: A total of 150 cases were examined, with mean age $32 \pm 5$ years and mean duration of infertility was $3.51 \pm 1.86$ years. Overall, $99(66 \%)$ cases had primary infertility. Tubal obstruction was seen in $92(61.33 \%)$ cases on HSG and $90(60 \%)$ on SSG. The sensitivity of SSG for tubal obstruction was $77.14 \%$, PPV 78.89\% and diagnostic accuracy $75.33 \%$ with $p=0.001$. The specificity and PPV was $100 \%$ in cases with age $30-40$ years with $p=0.001$. The diagnostic accuracy in multiparous women was 81.82 . $(\mathrm{p}=0.001)$

Conclusion: Saline infused sono hysterosalpingography revealed high sensitivity, specificity, PPV, NPV and diagnostic accuracy, which were comparable with conventional hysterosalpingography.

Key words: Infertility; Tubal blockage; Saline infused Sonohysterosalpingography (SSG); Hysterosalpingography (HSG); Diagnostic accuracy.
\end{abstract}

Article Citation: Mustafa Z, Wahid H, Majeed S, Rashid A. Saline Infused Sono-Hysterosalpingography; A Step Forward in the Diagnosis of Infertility Due to Tubal Blockage. JSZMC 2020;11(1):7-11

\section{Introduction}

Infertility is defined as the failure to conceive after one year of regular unprotected intercourse. It affects $10 \%$ to $15 \%$ of couples. ${ }^{1}$ Main causes of infertility in women include an-ovulatory cycles, a tubal or peritoneal factor, uterine and cervical pathologies and idiopathic infertility. ${ }^{2}$ The role of a tubal factor in infertility is increasing, and currently, it determines about $10 \%$ to $50 \%$ of all infertility cases. ${ }^{3}$ There are multiple etiologic factors responsible for the involvement of the fallopian tubes in infertility, which include tubal damage from pelvic inflammatory disease (PID), the use of intrauterine devices, a history of a perforated appendicitis, ectopic pregnancy, and septic abortion. ${ }^{1}$ Tubal adhesions and tubal obstruction can also be due to endometriosis and previous surgical trauma. ${ }^{2}$
Infertility investigation in women, reviews the morphologic, physiologic, functional and pathologic aspects of the fallopian tubes and female reproductive system. ${ }^{3}$ Sono hysterosalpinography (SSG) detects tubal blockage, while normal saline is infused through the folley's catheter in the uterine cavity. ${ }^{4}$ It can be used as primary technique for detection of tubal obstruction so that it may alleviates the need for invasive investigations as hysteroscopy particularly in IVF centers as this technique also offers the opportunity to rule out endometrial canal pathology simultaneously like polyps or adhesions etc. ${ }^{5}$

It is easier, time efficient investigative modality and has more acceptability and well tolerated as compared to other investigative methods and can be considered as screening tool as compared to HSG. ${ }^{6,7}$ Due to limited resources, most of infertility cases

1 Department of Radiology, Sheikh Zayed Medical College/Hospital, Rahim Yar Khan, Pakistan.

Correspondence: Dr Zaheer Mustafa, Associate Professor of Radiology, Sheikh Zayed Medical College / Hospital, Rahim Yar Khan, Pakistan.

Email: zaheermustafa1@gmail.com

Phone:+92-300-9670650

Received: 16-09-2019

Reviewed: 05-12-2019 
may be ignored or patient would have to travel a long distance to get hystero-salpingography (HSG), which is routinely used for establishment of diagnosis and needs a dedicated radiology unit. ${ }^{8}$ Most commonly this facility is available at tertiary health care systems. At the same time this procedure has hazards of ionizing radiations. Although laparoscopic chromopertubation is also an option as it has high diagnostic yield further more corrective surgery can also be performed simultaneously but again it is not freely available facility nor its expertise. ${ }^{4-7}$ Being an operative procedure it poses patients to many surgical complications. ${ }^{8-11}$

Ultrasound guided hysterosalpingography using normal saline as source of contrast can be used as an OPD based procedure especially in unprivileged areas as no special set up is needed. ${ }^{12}$ No special contrast is needed which further reduces the cost and secures the patient from hazards of iodinated contrast used in conventional HSG like contrast allergy and anaphylactic shock etc. This study was conducted to determine the diagnostic accuracy of saline infused Sonohysterosalpingohgraphy, for detection of fallopian tube blockage, in cases with infertility taking conventional hysterosalpingo-graphy as gold standard.

\section{Methodology}

This descriptive, cross sectional study was performed from $1^{\text {st }}$ May, to $30^{\text {th }}$ November, 2017, after approval from local ethical review committee. A total 150 patients fulfilling the inclusion criteria such as; all females having age 20 to 40 years irrespective of gravida and parity with suspected tubal obstruction related infertility, irrespective of primary and secondary; of at least one year, were included as assessed by history and medical record, were included. An informed written consent was taken.

Socio demographic data like age (in years), weight in kilogram, height in meters and BMI, was taken and other data like duration of infertility, type of infertility (primary/secondary), gravida, parity, history of any abdominal surgery, abortion and use of intrauterine contraceptive device (IUCD), were recorded on a specially designed proforma.

Patient was called between $5^{\text {th }}$ to $14^{\text {th }}$ day of her menstrual cycle. On day first saline infused sono hysterosalpingography was performed. Patient's endometrial canal was cannulated with folley's catheter and 10 to $50 \mathrm{ml}$ of sterilized normal saline was infused. Fallopian tubes were visualized simultaneously while performing real time imaging using trans-abdominal approach. Presence of fluid in pouch of Douglas was considered as patent fallopian tubes. The absence of spillage at fimbrial ends was labelled as tubal blockage. One $\mathrm{ml}$ steroid was given diluted with $5 \mathrm{ml}$ normal saline while performing saline infused sono-hysterosalpingography to avoid any future endometrial adhesion or inflammation due to endometrial irritation.

Similarly next day patient underwent conventional HSG. Urograffin 5-10 $\mathrm{ml}$ was given through cannula into endometrial cavity and radiographs of pelvis AP view were taken at baseline and then after 5 and 15 minutes. Furthermore, to avoid procedure related infection antibiotic cover with capsule Vibramycin $100 \mathrm{mg}$ B.D and Tab. Flagyl $400 \mathrm{mg}$ T.D.S was given for 5 days with Tab Ponstan for analgesia after the procedures. Data analysis was done by SPSS version 20.

\section{Results}

In this study, a total 150 cases were examined. The mean age was $32 \pm 5$ years. The mean duration of infertility was $3.51 \pm 1.86$ years. There were $99(66 \%)$ cases that had primary infertility. There were 22 $(14.67 \%)$ cases with previous history of abdominal surgery, 57 (38\%) had history of abortion and 31 $(21.99 \%)$ cases that had prior history of IUCD. Tubal obstruction was seen in $92(61.33 \%)$ cases on HSG and $90(60 \%)$ on SSG. The sensitivity of SSG for tubal obstruction was $77.14 \%$, PPV was $78.89 \%$ and diagnostic accuracy was $75.33 \%$ with $\mathrm{p}=0.001$ as in table I. The specificity and PPV was $100 \%$ in cases with age $30-40$ years with $\mathrm{p}=0.001$. (Table II) In cases with BMI less than 30 there was significantly better accuracy seen in $100 \%$ of cases with SSG and reverse was seen in BMI more than this as in table III. In terms of duration and type of infertility there was significant difference in both the parameters. The diagnostic accuracy in multiparous women was $81.82(\mathrm{p}=0.001)$. There were significant better diagnostic accuracies regarding lesser number of parity, and where there was no history of abdominal surgery, abortion and previous IUCD. 
Table I: Diagnostic Accuracy of SSG for Detection of Tubal Blockage $(n=150)$

\begin{tabular}{|c|c|c|c|}
\hline \multirow{2}{*}{$\begin{array}{c}\text { Obstruction } \\
\text { on SSG }\end{array}$} & \multicolumn{2}{|c|}{ Obstruction on HSG } & P.value \\
\cline { 2 - 3 } & Yes & No & \\
\hline \multirow{2}{*}{ Yes } & TP & FP & \multirow{2}{*}{0.01} \\
& 71 & 19 & \\
\hline \multirow{2}{*}{ No } & FN & TN & \\
& 21 & 39 & \\
\hline
\end{tabular}

$\mathrm{TP}=$ True positive $\quad \mathrm{TN}=$ True negative

$\mathrm{FN}=$ False negative $\quad \mathrm{FP}=$ False positive

Sensitivity $=77.17, \quad$ Specificity $=67.24$,

$\mathrm{PPV}=78.89, \quad \mathrm{NPV}=65$,

Accuracy $=73.33$

Table II: Diagnostic Accuracy of SSG for Detection of Tubal Blockage with Respect ro Age Groups $(n=150)$

\begin{tabular}{|c|c|c|c|c|}
\hline \multirow{2}{*}{$\begin{array}{l}\text { Age } \\
\text { Groups } \\
\text { (years) }\end{array}$} & \multirow[t]{2}{*}{$\begin{array}{c}\text { Obstruction } \\
\text { on SSG }\end{array}$} & \multicolumn{2}{|c|}{$\begin{array}{c}\text { Obstruction } \\
\text { on HSG }\end{array}$} & $\begin{array}{c}p \\
\text { value }\end{array}$ \\
\hline & & Yes & No & \multirow{3}{*}{0.92} \\
\hline \multirow{2}{*}{ 20-29 } & Yes & $\begin{array}{l}\mathrm{TP} \\
20\end{array}$ & $\begin{array}{l}\text { FP } \\
19\end{array}$ & \\
\hline & No & $\begin{array}{l}\text { FN } \\
10\end{array}$ & $\begin{array}{l}\text { TN } \\
09\end{array}$ & \\
\hline \multirow{2}{*}{$30-40$} & Yes & $\begin{array}{l}\mathrm{TP} \\
20\end{array}$ & $\begin{array}{l}\text { FP } \\
19\end{array}$ & \multirow{2}{*}{0.001} \\
\hline & No & $\begin{array}{c}\text { FN } \\
10\end{array}$ & $\begin{array}{l}\text { TN } \\
09\end{array}$ & \\
\hline
\end{tabular}

$\mathrm{TP}=$ True positive $\quad \mathrm{TN}=$ True negative

$\mathrm{FN}=$ False negative $\quad \mathrm{FP}=$ False positive

For age group 20-29 years

Sensitivity $=66.67, \quad$ Specificity $=32.14$,

$\mathrm{PPV}=51.28, \quad \mathrm{NPV}=47.37$,

Accuracy $=50$

For age group 30-40 years

Sensitivity $=82.26, \quad$ Specificity $=100$,

$\mathrm{PPV}=100, \quad \mathrm{NPV}=73.17$,

Accuracy $=88.04$
Table III: Diagnostic Accuracy of SSG for Detection of Tubal Blockage with Respect to BMI $(n=150)$

\begin{tabular}{|c|c|c|c|}
\hline \multirow{2}{*}{ Obstruction on SSG } & \multicolumn{2}{|c|}{$\begin{array}{c}\text { Obstruction on } \\
\text { HSG }\end{array}$} & \multirow{2}{*}{$\begin{array}{c}\text { P } \\
\text { value }\end{array}$} \\
\cline { 2 - 3 } & Yes & No & \\
\hline \multirow{2}{*}{ Yes } & TP & FP & \multirow{2}{*}{0.01} \\
\hline \multirow{2}{*}{ No } & 71 & 19 & \\
\hline & FN & TN & \\
\hline
\end{tabular}

$\mathrm{TP}=$ True positive

$\mathrm{TN}=$ True negative

$\mathrm{FN}=$ False negative $\quad \mathrm{FP}=$ False positive

Sensitivity $=77.17, \quad$ Specificity $=67.24$, $\mathrm{PPV}=78.89, \quad \mathrm{NPV}=65$,

Accuracy $=73.33$

\section{Discussion}

It was seen that obstruction irrespective of the site on SSG was seen in $90(60 \%)$ of the cases while on HSG it was seen in $92(61.33 \%)$ of the cases. This reveals that the both the modalities were comparable in terms of detection of the tubal blockage. The sensitivity of SSG for tubal obstruction was $77.14 \%$, PPV was $78.89 \%$ and diagnostic accuracy was $75.33 \%$ with $\mathrm{p}=0.001$. These findings were comparable to previous study with slighter lower accurate results by a study done by Dasan TA et al. ${ }^{9}$ In their study, as compared to HSG, the sensitivity, specificity, positive predictive value, and negative predictive values (NPVs) of SSG in detecting tubal patency were $94.28 \%, 75 \%, 97.05 \%$, and $50 \%$, respectively.

The sensitivities of SSG in diagnosing tubal patency were similar to other studies, Inki et $\mathrm{al}^{10}(90.2 \%)$, Deichert et $\mathrm{al}^{11}(89 \%)$, whereas the specificities obtained were slightly higher in Inki et $\mathrm{al}^{10}(83.3 \%)$ and Deichert et $\mathrm{al}^{11}(100 \%)$ as compared to the present study $(66.66 \%)$.

In another study, they focused on correlation between SSG and HSG for establishment of tubal patency in a study by Madhok $\mathrm{R}$ et $\mathrm{al}^{12}$ and it was observed that there was 92.3\% agreement (Kappa value $=0.923$, Standard error $=0.437,0.95 \mathrm{CI}=$ 0.8373-1) between SSG and HSG which suggests that SSG is at least similar to or slightly better to HSG in its effectiveness for evaluating tubal patency. In the present study, the SSG revealed better results 
than HSG in many cases. This factor can be explained by the fact that, the injection of the contrast led to spasm of the fallopian tubes which may be falsely interpreted as tubal blockage. But in SSG tubal spasm usually not occurred and false results can be avoided.

These findings were in contrast to a studies done by Oguntoyinbo AE, Amok AOD and Komolafe reported that there is no statistically significant difference $(p=0.237)$ between the results of the two methods (HSG and SSG). SSG is found to be a reliable, relatively inexpensive diagnostic and therapeutic (guided hydrotubation) procedure in the management of female infertility. ${ }^{13}$

The specificity and PPV was $100 \%$ in cases with age 30-40 years with $p=0.001$ and the cases with BMI less than 30 where there was accuracy of $100 \%$ seen in cases with SSG as compared to HSG. This can be explained by the factor of lesser BMI and better visualization of fallopian tubes as compared to the females with higher BMI where there is difficulty in visualization as fat in abdominal wall attenuate ultrasound beam making its penetration into pelvic cavity difficult.

In terms of duration and type of infertility there was significant difference in both the parameters. The diagnostic accuracy in multiparous women was $81.82(p=0.001)$ as and furthermore there was significant better diagnostic accuracies regarding lesser number of parity, and where there was no history of abdominal surgery, abortion and previous IUCD with saline infused sono hysterosalpingography as compared to HSG. The data is lacking regarding this extensive evaluation about these above mentioned parameters. These are the reasons of overall better prediction of SSG as compared to HSG for tubal obstruction. HSG revealed better prediction of tubal blockage in cases that had previous history of abdominal surgery, abortion and IUCD. This can be explained as previous surgeries lead to disrupted anatomy and needing more saline to be infused to detect the structural changes as compared to HSG where it was still possible with $5-10 \mathrm{ml}$ of urograffin and was found a better modality.

In contrast to this there were many strengthening points that this study used a newer modality in the form of s a lin e infused so no hysterosalpingography and it also extensively evaluated various confounding variables like gravida, parity, duration and types of infertility which were not studied before.

\section{Conclusion}

Saline infused sono-hysterosalpingography is safe and reliable for diagnosis of tubal blockage. It has advantage over conventional hysterosalpingography as it has no ionizing radiation, less chances of tubal spasm and easy availability. Sensitivity and specificity of SSG is comparable with conventional hysterosalpingography.

\section{Author Contribution}

ZM: Conception of work, design of work and revising. HW: Design of work, Acquisition and analysis of data and drafting. SM: Interpretation of data and revising. AR: Interpretation of data, revising.

All authors critically revised and approve its final version.

\section{Conflict of interest: None \\ Resources of funding: Self}

\section{References}

1. Aflatoonian A, Seyedhassanin SM, Tabibnejad N. The epidemiological and etiological aspects of infertility in Yazd province of Iran. Iran J Reprod Med 2009; 7(3): 117-22.

2. Abbas S, Malik A, Ahmed E. Frequency of tubal spasm during hysterosalpingography. Pak J Med Health Sci 2015; 9(1): 259-62.

3. Al-Subhi T, Al-Jashnmi TN, Al-Khaduri M, Gowri V. Prevalence of tubal obstruction in the hysterosalpingogram of women with primary and secondary infertility. J Reprod Infertil 2013; 14(4): 214-16.

4. Khatuja R, Mehta S, Rajaram S, Goel G. Role of laparoscopy in infertility: revisited.Eur J Obsetet Gynecol Reprod Biol 2012; 16(4): 118-22.

5. Usmani Y, Pandey VD, Ekramullah, Rashid S, Yadav Y. A comparative Study between sonosalphingography and laparoscopic chromopertubation for tubal evaluation. Sch J App Med Sci 2016; 4(6): 2266-70.

6. Pandit SP, Adhikari BB, Pandit S. Comparison of sonosalpingography and X-ray hysterosalpingography in the sub-fertile women. Post Grad Med J Nans 2011; 11(1): 9-11.

7. Sambharam K, Rode S, Bhalerao A. Comparison of sonosalphingography and laparoscopy in evaluation of tubal patency in infertility patients. Int J Sci Res Pub 2015; 5(7): 1-5.

8. Malik B, Patil S, Boricha BG, Kurkal N, Chaoudhry M. A comparative study of the efficacy of sonosalpingography and hysterosalpingo-gram to test the tubal patency in all women with primary and secondary infertility. Ultrasound Q 2014; 30(2): 139-43 
9. Dasan T A, Basawaraj N G. A comparative study of saline infused sonohysterography and conventional hysterosalpingography in the evaluation of female infertility. West Afr J Radiol 2016;23: 124-9

10. Inki P, Palo P, Anttila L. Vaginal sonosalpingography in the evaluation of tubal patency. Acta Obstet Gynecol Scand 1998; 77: 978-82.

11. Deichert U, Schlief R, van de Sandt M, Daume E. Transvaginalhysterosalpingo-contrast sonography for the assessment of tubal patency with gray scale imaging and additional use of pulsed wave Doppler. Fertil Steril 1992; 57: 62-7.
12. Madhok R, Taneja V. Role of sonosalpingogram in correlation to hyeterosalpingogram in assessment of infertility. Int J Reprod, Contracept, Obstet Gynecol 2016; 5(6): 1936-43.

13. Oguntoyinbo AE, Amok AOD and KomolafeOF. Sonographic assessment of fallopian tube patency in the investigation of female infertility in Ilorin, Nigeria. Afr J Reprod Health 2001; 5(1): 100-5 